\title{
Severe Behçet's disease equally affects both genders in Egyptian patients: A multicentre retrospective follow-up study
}

\author{
D.H.S. Attia ${ }^{1}$, R.A. Abdel Noor ${ }^{2}$ \\ ${ }^{1}$ Rheumatology and Rehabilitation Department, Faculty of Medicine, Cairo University, Cairo, Egypt; \\ 2Internal Medicine \& Rheumatology Department, Faculty of Medicine, Tanta University, Tanta, Egypt
}

\begin{abstract}
SUMMARY
Behçet's disease is a relapsing multisystemic disease. Its highest prevalence is seen along the Silk Road. While several studies reported gender disparities, others didn't. Scarce data are available about the Arabs and the gender differences detected in some ethnicities could not be applied to others. Our study aimed to detect gender differences among a cohort of adult Egyptian patients with Behçet's disease.

Medical files of 255 adult patients diagnosed with Behçet's disease at the Rheumatology and Rehabilitation Department of Kasr Al-Aini Hospital, Cairo University and the Internal Medicine Department of Tanta University, between 2002 and 2018, were retrospectively reviewed. The demographic features, the cumulative clinical features, the use, if any, of an intravenous pulse of methylprednisolone and immunosuppressive/biological drugs, and the frequency of the cumulative damage to the different organ systems were described. The disease severity score was calculated as well.

The study revealed a prominent male predominance; the male to female ratio was 6.7:1. Acne/pseudofolliculitis was more common in males ( $28.6 \%$ vs $13.2 \%, p=0.046)$; the same was observed regarding any vascular involvement and peripheral venous disease ( $36.3 \%$ vs $18.4 \%, \mathrm{p}=0.03$ and $30.4 \%$ vs $13.2 \%, \mathrm{p}=0.03$, respectively). On the other hand, encephalitis and cranial nerve lesions were more prevalent in females $(15.8 \% \mathrm{vs} 6 \%, \mathrm{p}=0.03$ and $10.5 \%$ vs $3.2 \%, \mathrm{p}=0.04$, respectively).

Severe Behçet's disease equally affects Egyptian males and females. BD should not be considered a benign disease in Egyptian females. The same quality of medical care should be equally offered to both genders.
\end{abstract}

Key words: Behçet's disease; Adamantiades disease; sex; gender; severity

Reumatismo, 2019; 71 (4): 218-225

\section{INTRODUCTION}

ehçet's disease (BD) is a chronic relapsing disease. It can affect any organ system with a predilection for the mucocutaneous, articular, ocular, vascular and neurological systems. Its etiopathogenesis is not clearly understood; but it is thought that BD stands midway between the autoinflammatory and autoimmune diseases (1). Being the commonest primary vasculitis in Egypt, BD was and still is an attractive topic of study (2).

Gender differences are described worldwide. In the Mediterranean region, males are more commonly affected, while females are mainly affected in the Far East (3). Various studies reported a higher major organ involvement rate, a greater disease severity and a worse prognosis in males. While several studies reported gender disparities (4-7), others didn't $(8,9)$. Moreover, scarce data are available about the Arab population; and gender differences detected in some ethnicities cannot be applied to others.

Hence, our study aimed to detect gender differences among a cohort of adult Egyptian patients with BD regarding the different demographic and clinical features, the degree of disease severity, and the frequency of cumulative damage to the different organ systems. Our hypothesis was that severe BD equally affects both genders in Egypt where the disease is endemic and tends to be fully expressed. 


\section{MATERIALS AND METHODS}

The study was conducted at the Rheumatology and Rehabilitation Department and Outpatient Clinic of Kasr Al-Aini Hospital, Cairo University; and the Internal Medicine and Rheumatology Department, Tanta University. Medical files of BD patients included in the Egyptian vasculitis cohort (2) were retrospectively reviewed. The 2006 International Criteria for BD were used for classification/reclassification of patients (10).

The demographic features in addition to the disease duration, the duration of follow-up and the frequency of delayed diagnosis were recorded. Disease duration was defined as the duration from the first disease manifestation until the last visit/death. Delayed diagnosis was defined as the elapse of a duration of more than 3 months between the time of classification criteria fulfillment and diagnosis; this duration was selected based on its influence on damage accrual (11).

The cumulative clinical characteristics reported throughout the disease course were recorded as well.

Disease severity was assessed using several indicators. The disease severity score was calculated as suggested by Yosipovitch et al., 1995 (12) and modified by Krause et al., 2001 (13). Any use of intravenous methylprednisolone (IV MP) or/and immunosuppressive/biological drugs was used as an indicator of disease severity. IV MP pulse referred to the IV infusion of 250-1000 mg methylprednisolone per day for 1 to 3 days (14). The development of organ damage was used as an indicator of disease burden and aggressiveness of treatment. Organ damage was defined as the development of a permanent organ system abnormality that is induced by the disease or its treatment (11).

The study was approved by the Research Ethics Committee of the Faculty of Medicine, Cairo University (N-30-2016). The study conformed to the provisions of the Declaration of Helsinki.

\section{Statistical analysis}

Categorical variables were described in terms of frequencies and percentages while numerical variables were described in terms of median and interquartile range (IQR) due to skewness of data. The chi-square test was used for the comparison between categorical variables with the calculation of the odds ratio (OR) and its $95 \%$ confidence interval $(\mathrm{CI})$. The $\mathrm{OR}$ was calculated as the odds of the event in females divided by the odds of the event in males. The MannWhitney test was used for the comparison between numerical variables. A p-value less than 0.05 was considered statistically significant. All statistical calculations were performed using SPSS (Statistical Package for the Social Science; SPSS Inc., Chicago, IL, United States of America) version 15 for Microsoft Windows.

\section{RESULTS}

The study included 255 patients, 217 $(85.1 \%)$ males and $38(14.9 \%)$ females with a male to female ratio of $6.7: 1$. The comparisons between males and females regarding age at disease onset and recruitment, disease duration, duration of follow-up, disease severity score, smoking history, and residence are shown in Table I. Ninety-seven (44.7\%) males and none of the females were smokers with a statistically significant difference between groups $(\mathrm{p}<0.001)$.

Delayed diagnosis was reported in 170 (78.3\%) males and 26 (68.4\%) females; the comparison between groups showed no significant difference $(\mathrm{p}=0.18, \mathrm{OR}=0.59$, 95\% CI= 0.3-1.3).

The frequencies of the cumulative different clinical characteristics evolving thoughout the disease course are shown in Table II with the comparison between both genders. According to the disease severity score, severe disease manifestations were reported in 167 (77\%) males and 25 (65.8\%) females; the comparison between both groups revealed no significant difference $(\mathrm{p}=0.14, \mathrm{OR}=0.58$, 95\% CI=0.27-1.2). There were no significant differences between males and females concerning any use of IV MP (46.5\% versus $44.7 \%, \mathrm{p}=0.84$, OR $=0.93,95 \% \mathrm{CI}=0.47-$ 1.86) and immunosuppressant/biological therapies $(93.1 \%$ versus $86.8 \%, \mathrm{p}=0.19$, $\mathrm{OR}=0.49,95 \% \mathrm{CI}=0.17-1.4)$. 
Table I - Demographic characteristics and Behçet's disease severity.

\begin{tabular}{|c|c|c|c|c|c|}
\hline & & $\begin{array}{l}\text { Males } \\
\mathrm{N}=217\end{array}$ & $\begin{array}{c}\text { Females } \\
\qquad=38\end{array}$ & $\mathbf{P}$ & $\begin{array}{c}\text { OR } \\
(95 \% \mathrm{Cl})\end{array}$ \\
\hline \multicolumn{2}{|c|}{ Age at onset (yr), median (IQR) } & $26(22-32)$ & $26.5(21-33)$ & 0.78 & \\
\hline \multicolumn{2}{|c|}{ Age at recruitment (yr), median (IQR) } & $34(28-40)$ & $35(27.7-41.2)$ & 0.97 & \\
\hline \multicolumn{2}{|c|}{ Disease duration (mo), median (IQR) } & $72(36-121.5)$ & $64.5(33-125)$ & 0.45 & \\
\hline \multicolumn{2}{|c|}{ Duration of follow-up (mo), median (IQR) } & $21(4.5-48)$ & $15(7.5-53.3)$ & 0.76 & \\
\hline \multicolumn{2}{|c|}{ Disease severity score, median (IQR) } & $7(5-11)$ & $6(4-9.25)$ & 0.06 & \\
\hline \multicolumn{2}{|l|}{ Smoking } & $84(38.7)$ & $0(0)$ & $<0.001$ & \\
\hline \multirow{2}{*}{ Residence } & Rural, N (\%) & $146(67.3)$ & $22(57.9)$ & \multirow{2}{*}{0.26} & \multirow{2}{*}{$0.7(0.3-1.4)$} \\
\hline & Urban, N (\%) & $71(32.7)$ & $16(42.1)$ & & \\
\hline
\end{tabular}

Yrs: years. mo: months. Comparisons were performed using the Mann-Whitney test for the numerical variables and the chi-square test for the categorical variables. OR=odds in females/odds in males. $p<0.05$ is considered statistically significant.

The frequencies of cumulative damage of the different systems are shown in Table III. Damage was reported in $165(76 \%)$ males and $25(65.8 \%)$ females with no significant difference between both groups $(\mathrm{p}=0.18, \quad \mathrm{OR}=0.6, \quad 95 \% \quad \mathrm{CI}=0.29-1.3)$. Among patients with ocular disease, nineteen $(14.3 \%)$ males and $4(19 \%)$ females developed unilateral/bilateral blindness; the comparison between the two groups showed no significant difference $(\mathrm{p}=0.57$, $\mathrm{OR}=1.4,95 \% \mathrm{CI}=0.43-4.7$ ).

During a median follow-up period of 20 months (IQR: 5-48), four deaths were reported, one female and two males; the comparison between both groups revealed an insignificant difference $(\mathrm{p}=0.39, \mathrm{OR}=3$, $95 \% \mathrm{CI}=0.3-32.9$ ).

\section{DISCUSSION}

The male to female ratio of our cohort was 6.7:1; a similar ratio of 5.37:1 was observed in another Egyptian study (15). However, a third Egyptian study reported a lower ratio of 1.7:1 (16); and a fourth one documented a higher ratio of 30.5:1 (17). Notably, those studies included smaller samples than ours. Male predominance was also reported in Iran, Turkey, Germany and Italy. The highest male to female ratio is seen in the Arab population $(5,15,18-20)$. On the contrary, females predominate in Korea, Brazil, France, the United Kingdom (UK) and the United States of America (USA) (8, 21-23).
In Japan, the results are controversial: One study reported male predominance; another one showed female prevalence; and a third one revealed no gender predilection (24-26). In this study, the age at onset wasn't different between males and females. On the other hand, Turkish studies are inconsistent: some reported that, the younger the age of onset, the higher the male to female ratio $(6,27)$; another one detected an earlier age of onset in females (28).

No gender difference was detected in this study concerning the mucocutaneous features except for acne/pseudofolliculitis which was more prevalent in males and the positive pathergy test, which was more common in females.

In contrast to these findings, studies from Turkey, Germany, Iran, Korea and Greece reported a higher prevalence and a greater severity of genital ulcers in females $(2,5,7$, $19,20,26,29-31)$. A high frequency of oral ulcers was reported in Korean and Turkish females $(3,7)$. However, another Turkish study reported that oral and genital ulcers equally affect both genders (6).

On the other side, several studies reported a male predilection concerning superficial thrombophlebitis $(6,23)$, folliculitis $(26$, 29), papulopustular rash $(3,5-7,19,20,28$, $32)$ and positive pathergy test $(5-7,19)$.

Korean, German, Turkish, and Jordanian females have a higher frequency of erythema nodosum (EN) $(3,5-7,19,20,28,32)$. However, Iranian (28) and other Korean 
Table II - Cumulative clinical characteristics frequency in Behçet's disease patients.

\begin{tabular}{|c|c|c|c|c|}
\hline Clinical characteristic & $\begin{array}{c}\text { Male } \\
\mathrm{N}=217\end{array}$ & $\begin{array}{c}\text { Females } \\
\mathrm{N}=38\end{array}$ & $p$ & $\begin{array}{c}\text { OR } \\
(95 \% \mathrm{Cl})\end{array}$ \\
\hline Constitutional & $44(20.3)$ & $6(15.8)$ & 0.52 & $0.73(0.3-1.9)$ \\
\hline Mucocutaneous & 213 (98.2) & $38(100)$ & 0.39 & \\
\hline Oral ulcers & $210(96.8)$ & $37(97.4)$ & 0.85 & $1.2(0.14-10.3)$ \\
\hline Genital ulcers & $190(87.6)$ & $35(92.1)$ & 0.42 & $1.7(0.48-5.7)$ \\
\hline Acne/pseudofolliculitis & $62(28.6)$ & $5(13.2)$ & $0.046^{*}$ & $0.37(0.14-1)$ \\
\hline EN & $43(19.8)$ & $8(21.1)$ & 0.86 & $1(0.46-2.5)$ \\
\hline Positive pathergy test ${ }^{\star *}$ & $12(25.5)$ & $6(60)$ & $0.03^{*}$ & $4.4(1-18.2)$ \\
\hline Articular & $84(38.7)$ & $13(34.2)$ & 0.59 & $0.82(0.39-1.7)$ \\
\hline Ocular & $133(61.3)$ & $21(55.3)$ & 0.48 & $0.78(0.39-1.6)$ \\
\hline Anterior uveitis & $82(37.8)$ & $12(31.6)$ & 0.46 & $0.76(0.36-1.6)$ \\
\hline Posterior uveitis & $94(43.3)$ & $17(44.7)$ & 0.87 & $1.1(0.53-2.1)$ \\
\hline Retinitis & $27(12.4)$ & $5(13.2)$ & 0.9 & $1.1(0.38-2.9)$ \\
\hline Retinal vasculitis & $49(22.6)$ & $8(21.1)$ & 0.84 & $0.91(0.39-2.1)$ \\
\hline Retinal artery thrombosis & $7(3.2)$ & $0(0)$ & 0.26 & \\
\hline Retinal vein thrombosis & $20(9.2)$ & $0(0)$ & 0.05 & \\
\hline Optic neuritis & $11(5.1)$ & $4(10.5)$ & 0.19 & $2.2(0.66-7.3)$ \\
\hline Ischemic Optic neuropathy & $1(0.5)$ & $0(0)$ & 0.68 & \\
\hline Vascular & $80(36.9)$ & $7(18.4)$ & $0.03^{*}$ & $0.39(0.16-0.92)$ \\
\hline DVT of limbs & $66(30.4)$ & $5(13.2)$ & $0.03^{*}$ & $0.35(0.13-0.93)$ \\
\hline Vena caval thrombosis & $15(6.9)$ & $0(0)$ & 0.09 & \\
\hline PAD & $12(5.5)$ & $0(0)$ & 0.14 & \\
\hline Aortic disease & $5(2.3)$ & $0(0)$ & $>0.999$ & \\
\hline Superficial thrombophlebitis & $27(12.4)$ & $4(10.5)$ & 0.74 & $0.83(0.27-2.5)$ \\
\hline Cardiac & $6(2.8)$ & $0(0)$ & 0.3 & \\
\hline Pulmonary & $22(10.1)$ & $2(5.3)$ & 0.4 & $0.49(0.11-2.2)$ \\
\hline$\forall$ & $12(5.5)$ & $0(0)$ & 0.14 & \\
\hline $\mathrm{PH}$ & $4(1.8)$ & $1(2.6)$ & 0.75 & $1.4(0.16-13.2)$ \\
\hline Pulmonary vessel disease & $13(6)$ & $1(2.6)$ & 0.4 & $0.42(0.05-3.3)$ \\
\hline Neurological & $51(23.5)$ & $12(31.6)$ & 0.29 & $1.5(0.7-3.2)$ \\
\hline Dural sinus thrombosis & $16(7.4)$ & $2(5.3)$ & 0.64 & $0.69(0.15-3.2)$ \\
\hline Encephalitis & $13(6)$ & $6(15.8)$ & $0.03^{*}$ & $2.9(1-8.3)$ \\
\hline Myelitis & $4(1.8)$ & $0(0)$ & 0.39 & \\
\hline Cerebrovascular disease & $24(11.1)$ & $5(13.2)$ & 0.7 & $1.2(0.43-3.4)$ \\
\hline Cranial neuropathy & $7(3.2)$ & $4(10.5)$ & $0.04^{*}$ & $3.5(1-12.7)$ \\
\hline GIT Perforation & $3(1.4)$ & $0(0)$ & 0.47 & \\
\hline Severe disease & $167(77)$ & $25(65.8)$ & 0.14 & $1.7(0.82-3.6)$ \\
\hline
\end{tabular}

EN: erythema nodosum, DVT: deep venous thrombosis, PAD: peripheral arterial disease. PE: pulmonary embolism. PH: pulmonary hypertension. GIT: gastrointestinal tract. ${ }^{*}$ Pathergy test was performed in 47 and 10 male and female patients, respectively. Comparisons were performed using the chi-square test. $\mathrm{OR}=$ odds in females/odds in males. ${ }^{*} \mathrm{p}<0.05$ is considered statistically significant. 
Table III - Cumulative damage frequency in Behçet's disease patients.

\begin{tabular}{|l|c|c|c|c|}
\hline & $\begin{array}{c}\text { Males } \\
\mathbf{N}=217\end{array}$ & $\begin{array}{c}\text { Females } \\
\mathbf{N}=38\end{array}$ & $\mathbf{p}$ & $\begin{array}{c}\text { OR } \\
(\mathbf{9 5 \%} \text { Cl) }\end{array}$ \\
\hline Any damage* $^{* *}$ & $165(76)$ & $25(65.8 \%)$ & 0.18 & $0.6(0.29-1.3)$ \\
\hline Musculoskeletal & $11(5.1)$ & $0(0)$ & 0.16 & \\
\hline Ocular & $65(30)$ & $7(18.4)$ & 0.15 & $0.53(0.22-1.3)$ \\
\hline Pulmonary & $19(8.8)$ & $2(5.3)$ & 0.47 & $0.58(0.13-2.6)$ \\
\hline Cardiac & $7(3.2)$ & $0(0)$ & 0.26 & \\
\hline Neurological & $17(7.8)$ & $4(10.5)$ & 0.58 & $1.4(0.4-4.4)$ \\
\hline Postphelbitic limb & $21(9.7)$ & $2(5.3)$ & 0.38 & $0.52(0.12-2.3)$ \\
\hline PAD & $12(5.5)$ & $0(0)$ & 0.14 & \\
\hline Aortic & $5(2.3)$ & $0(0)$ & 0.35 & \\
\hline Chronic vena caval obstruction & $15(6.9)$ & $0(0)$ & 0.09 & \\
\hline GIT & $3(1.4)$ & $0(0)$ & 0.47 & \\
\hline
\end{tabular}

PAD: peripheral arterial disease. GIT: gastrointestinal tract. Comparisons were performed using the chi-square test. OR=odds in females/odds in males. ${ }^{*} \mathrm{p}<0.05$ is considered statistically significant. ${ }^{*}$ Any damage includes others i.e. diabetes mellitus surgery, chronic unresolving infections, chronic cyclosporine nephropathy ...etc.

(29) studies showed a higher prevalence of EN in males.

Male and female patients showed a similar frequency of articular involvement in this study. In disagreement with this result, articular disease was more frequently observed in females from Korea, Germany, Turkey, and Greece $(3,5,28-31)$. However, another German study reported a similar frequency of arthritis in both genders while another Turkish study showed a higher frequency in males (6). In an Iranian study, monoarthritis was more frequently reported in men (26).

In this cohort, vascular involvement was more common in males. Peripheral and central venous diseases were more commonly observed in males in many studies supporting our findings. The same was reported on arterial involvement $(3,5-7$, 19, 20, 26, 28, 32). Furthermore, the severity of vascular disease was reported to be greater in males $(4,6)$.

The frequency of ocular involvement was comparable in males and females in the current study. In contrast, ocular disease was more commonly reported in men from Korea, Turkey, Iran and Italy (3, 4, 6, 7, 19, 26, 28, 33, 34). Moreover, male gender was associated with a greater severity and a worse prognosis of ocular disease in Korea,
Germany, Turkey, Iran and France: it usually takes the picture of bilateral panuveitis and retinal vasculitis in males, and the picture of isolated anterior uveitis in females (3, 5, 6, 19, 20, 26, 27, 35-37). However, other Turkish and Korean studies revealed no gender disparities $(7,29)$.

In the current study, male and female patients had comparable frequency of cardiac and pulmonary involvement. A German study showed a higher frequency of cardiac disease in males (4). In contrast, an Iranian study reported an increased prevalence of angina pectoris and murmurs in females (26). A higher frequency of pulmonary involvement was reported in men $(4,19,33)$. In this study, encephalitis and cranial nerve involvement developed more frequently in females. In disagreement with these results, the frequency of nervous system affection was reported to be higher in males from Turkey, Iran, Jordan, Iraq, Italy, UK and Tunisia $(4,6,9,18,26,32,33,35$, 37-41). Furthermore, a greater severity of neurological involvement was reported in males (7). Turkish and Iranian females showed an exceptionally higher prevalence of isolated headaches $(9,26,28)$. On the other hand, Turkish study reported no gender predilection (6).

Regarding gastrointestinal (GIT) involve- 
ment, no gender preference was reported in two studies $(7,20)$ supporting our results. In the current study, the BD severity score was comparable in males and females. Moreover, there were no gender differences regarding the frequency of any use of IV MP and immunosuppressant/biological agents, and the mortality rate as indicators of disease severity. Furthermore, there was no gender difference regarding the cumulative damage as a reflection of the disease burden and a consequence of aggressive treatment. In disagreement with these findings, it has been reported that males represent the greater proportion of patients presenting with major organ involvement including the ocular, neurological, cardiovascular and neurological systems (3-7, 21, $22,28,29,37-39)$; they also have a higher mortality rate $(35,42,43)$.

Several studies tried to explain the gender disparities of BD. An association between disease severity (44); and human leukocytic antigen (HLA)-B5 and HLA-B51 was more frequently detected in male patients (26). HLA class I typing was performed in a subgroup of our cohort by Elfishawi et al. (45) where 57 patients (51 males and 6 females) were tested. HLA-B5 was not detected in either group while HLA-B51 was detected in $26.5 \%$ and $25 \%$ of males and females, respectively, with no significant difference $(\mathrm{p}=0.91)$ [data not published]. The equal frequency of HLA-B5 and 51 in the aforementioned study could explain the comparability of the disease severity in both genders.

Concerning gender-related hormonal influences, it was suggested that the higher prevalence of folliculitis, papulopustular lesions and positive pathergy test in men could be explained by the testosterone-induced neutophil hyperactivity (46).

Regarding the environmental exposures, some authors suggested that the higher disease severity in male patients could be explained by the greater prevalence of smoking among men (47). In this study, none of our female patients was smoker despite the equal disease severity in men and women. In disagreement with the aforementioned studies that reported gender disparities of
$\mathrm{BD}$, and in agreement with our results, other studies from Korea, Iran, Turkey and Saudi Arabia failed to reveal gender differences $(8,9,48,49)$. In another Korean study, no gender differences were found regarding the frequency of major organ involvement except for uveitis which was more commonly reported in males (29).

To our knowledge, this study seems to be the first study specifically tackling this topic in Egyptian BD patients.

One may argue that Egyptian female patients could have limited access to health care services; and this could confound our results. However, the study was conducted in hospitals that offer free of charge services to all patients by a team of male and female physicians.

\section{CONCLUSIONS}

Our study revealed that there is no gender difference regarding the disease demographic characteristics. Females tend to have a higher frequency of neurological involvement while males tend to have more frequent vascular involvement. The disease severity and damage were comparable in males and females. In contrast to the studies derived from the non-Arab populations, BD should not be considered a benign disease in Egyptian females. Attention, screening, close follow-up and the institution of aggressive therapy should be equally offered to Egyptian male and female patients. Further multicenter studies including a larger population size and HLA-B5 and HLA-B51 typing are recommended.

\section{REFERENCES}

1. Pineton de Chambrun M, Wechsler B, Geri $\mathrm{G}$, et al. New insights into the pathogenesis of Behçet's disease. Autoimmun Rev. 2012; 11: 687-98.

2. Attia DHS, Abdel Noor RA, Salah S. Shedding light on vasculitis in Egypt: a multicenter retrospective cohort study of characteristics, management, and outcome. Clin Rheumatol. 2019; 38: 1675-84.

3. Bang DS, Oh SH, Lee KH, et al. Influence of sex on patients with Behçet's disease in Korea. J Korean Med Sci. 2003; 18: 231-5. 
4. Shimizu T, Ehrlich GE, Inaba G, Hayashi K. Behçet's disease. Semin Arthritis Rheum. 1979; 8: 223-60.

5. Bonitsis NG, Nguyen LBL, LaValley MP, et al. Gender-specific differences in Adamantiades-Behçet's disease manifestations: an analysis of the German registry and meta-analysis of data from the literature. Rheumatology. 2015; 54: 121-33.

6. Yazici H, Tüzün Y, Pazarlih H, et al. Influence of age of onset and patient's sex on the prevalence and severity of manifestations of Behçet's syndrome. Ann Rheum Dis. 1984; 43: 783-9.

7. Ucar-Comlekoglu D, Fox A, Nida Sen H. Gender Differences in Behçet's Disease Associated Uveitis. J Ophthalmol. 2014; 2014: 820710.

8. Bang D, Yoon KH, Chung HG, et al. Epidemiological and clinical features of Behçet's Disease in Korea. Yonsei Med J. 1997; 38: 428-36.

9. Davatchi F, Chams-Davatchi C, Shams H, et al. Adult Behçet's disease in Iran: analysis of 6075 patients. Int J Rheum Dis. 2016; 19: 95-103.

10. Davatchi F, Schirmer M, Zouboulis C, et al. On behalf of the International Team for the Revision of the International Study Group Criteria for Bechet's disease. Evaluation and Revision of the International Study Group Criteria for Behcet's disease. Proceedings of the American College of Rheumatology Meeting; November 2007; Boston, MA. Abstract 1233.

11. Exley AR, Bacon PA, Luqmani RA, et al. Development and initial validation of the Vasculitis Damage Index for the standardized clinical assessment of damage in the systemic vasculitides. Arthritis Rheum. 1997; 40: 371-80.

12. Yosipovitch G, Shohat B, Bshara J, et al. Elevated Serum Interleukin 1 Receptors And Interleukin 1B In Patients With Behcet's Disease: Correlations With Disease Activity And Severity. Isr J Med Sci. 1995; 31: 345-8.

13. Krause I, Mader R, Sulkes J, et al. Behçet's disease in Israel: the influence of ethnic origin on disease expression and severity. J Rheumatol. 2001; 28: 1033-6.

14. Buttgereit F, da Silva JA, Boers M, et al. Standardized nomenclature for glucocorticoid treatment regimens: current questions and tentative answers in rheumatology. Ann Rheum Dis. 2002; 61: 718-22.

15. Assaad-Khalil SH, Kamel FA, Ismail EA. Starting a regional registry for patients with Behçet's Disease in North West Nile Delta region in Egypt. Behcet's Disease. Hamza M editor. Tunis: Pub Adhoua; 1997; 173-6.

16. El-Najjar AR, Abou El-Soud AM, Amar HA, Diab MA. Clinical characteristics and disease activity of Behçet's disease patients in Zagazig, Egypt. Egypt Rheumatol. 2015; 37: 191-6.
17. El Menyawi MM, Raslan HM, Edrees A. Clinical features of Behcet's disease in Egypt. Rheumatol Int. 2009; 29: 641-6.

18. Karincaoglu Y, Coskun BK, Seyhan M, Aki T. Demographical and Clinical Characteristics of Behçet's Disease Patients in Malatya And Elazig. Turkiye Klinikleri J Dermatol. 2005; 15: 65-70.

19. Tursen U, Gurler A, Boyvat A. Evaluation of clinical findings according to sex in 2313 Turkish patients with Behçet's disease. Int J Dermatol. 2003; 42: 346-51.

20. Zouboulis CHC, Djawari D, Kirch W. Adamantiades-Behçet's disease in Germany. In: Behçet's Disease. Godeau P and Wechsler B editors. $1^{\text {st }}$ ed. Amsterdam, The Netherlands: Elsevier Science; 1993; 193-6.

21. Scherer MA, Vitral N, Orefice F. Clinical study of Behçet's Disease in Brazil. In: Behçet's Disease. Godeau P, Wechsler B editors. Amsterdam: Elsevier Science Publishers; 1993; 181-4.

22. Hamzaoui A, Klii R, Harzallah O, et al. Behçet's disease in women. Rev Méd Intern. 2012; 33: 552-5.

23. Davis GL, Brissett D. Experiencing Behçet's Disease: a view from 245 patients. In: Behçet's Disease. Godeau P, Wechsler B editors. Amsterdam: Elsevier Science Publishers; 1993 pp 211-4.

24. Ideguchi H, Suda A, Takeno M, et al. Behçet disease: evolution of clinical manifestations. Medicine. 2011; 90: 125-32.

25. Nakae K, Masaki F, Hashimoto T, et al. Recent epidemiological features of Behçet's disease in Japan. In: Behçet's Disease. Godeau P, Wechsler B editors. Amsterdam: Elsevier Science Publishers, Excerpta Medica; 1993; 145-51.

26. Davatchi F, Shahram F, Chams-Davatch C, et al. Behçet's disease: is there a gender influence on clinical manifestations? Int J Rheum Dis. 2012; 15: 306-14.

27. Tugal-Tutkun I. Behçet's uveitis. Middle East Afr J Ophthalmol. 2009; 16: 219-24.

28. Cansu DU, Kaşifoğlu T, Korkmaz C. Do clinical findings of Behçet's disease vary by gender?: A single-center experience from 329 patients. Eur J Rheumatol. 2016; 3: 157-60.

29. Ryu HJ, Seo MR, Choi HJ, Baek HJ. Clinical phenotypes of Korean patients with Behçet disease according to gender, age at onset, and HLA B51. Korean J Intern Med. 2018; 33: 1025-31.

30. Zouboulis CC, Vaiopoulos G, Marcomichelakis $\mathrm{N}$, et al. Onset signs, clinical course, prognosis, treatment and outcome of adult patients with Adamantiades - Behçet's disease in Greece. Clin Exp Rheumatol. 2003; 21: S19-S26.

31. Sula B, Batmaz B, Ucmak D, et al. Demographical and Clinical Characteristics of Be- 
hçet's Disease in Southeastern Turkey. J Clin Med Res. 2014; 6: 476-81.

32. Madanat W, Fayyad F, Verity D, Zureikat H. Influence of sex on Behçet's disease in Jordan. In: Behçet's disease: Proceedings of the 8th and 9th International Conference on Behçet's disease. Bang D, Lee ES editors. Seoul, Design Mecca Publishing; 2001; 90-3.

33. Davatchi F, Shahram F, Chams H, et al. The influence of gender on the severity and the outcome of ocular lesions in Behçet's disease. Adv Exp Med Biol 2003; 528: 67-71.

34. Pivetti-Pezzi P, Accorinti M, La Cava M, et al. Ocular features of Behçet's disease in Italy. In: Behçet's Disease, proceedings of the Sixth International Conference on Behçets Disease, Paris. Godeau P, Wechsler B editors. Amsterdam: Elsevier Science Publishers; 1993; 615-7.

35. Dilsen N, Koniçe M, Aral O, et al. Risk factors for vital organ involvement in Behçet's disease. In: Behçet's Diseasel. Wechsler B, Godeau P editors. Amsterdam: Elsevier Science Publishers; 1993; 165-70.

36. Saadoun D, Wechsler B, Desseaux K, et al. Mortality in Behcet's disease. Arthritis Rheum. 2010; 62: 2806-12.

37. Al-Araji A, Sharquie K, Al-Rawi Z. Prevalence and patterns of neurological involvement in Behçet's disease: a prospective study from Iraq. J Neurol Neurosurg Psychiat. 2003; 74: 608-13.

38. Talarico R, d'Ascanio A, Figus M, et al. Behçet's disease: features of neurological involvement in a dedicated centre in Italy. Clin Exper Rheumatol. 2012; 30: S69-S72.

39. Al-Araji A, Kidd DP. Neuro-Behçet's disease: epidemiology, clinical characteristics, and management. Lancet Neurol. 2009; 8: 192-204.
40. Seyahi E, Yazici H. Prognosis in Behçet's syndrome. In: Behçet's Syndrome. Yazici Y, Yazici H editors. New York, NY, USA: Springer; 2010: 285-95.

41. Houman MH, Bellakhal S, Ben Salem T, et al. Characteristics of neurological manifestations of Behçet's disease: a retrospective monocentric study in Tunisia. Clin Neurol Neurosurg. 2013; 115: 2015-8.

42. Davatchi F, Shahram F, Chams C, et al. The influence of gender on the frequency of clinical symptoms in Behçet's disease. Adv Exp Med Biol. 2003; 528: 65-6.

43. Gül A. Behçet's disease as an autoinflammatory disorder. Curr Drug Target Inflam Allerg. 2005; 4: 81-3.

44. Savey L, Resche-Rigon M, Wechsler B, et al. Ethnicity and association with disease manifestations and mortality in Behçet's disease. Orphanet J Rare Dis. 2014; 9: 42.

45. Elfishawi MM, Elgengehy F, Mossallam G, et al. HLA Class I in Egyptian patients with Behçets disease: new association with susceptibility, protection, presentation and severity of manifestations. Immunol Investig. 2019; 48: 121-9.

46. Yavuz S, Ozilhan G, Elbir Y, et al. Activation of neutrophils by testosterone in Behçet's disease. Clin Exp Rheumatol. 2007; 25: S46-51.

47. Özer HT, Günesaçar R, Dinkçi S, et al. The impact of smoking on clinical features of Behçet's disease patients with glutathione Stransferase polymorphisms. Clin Exper Rheumatol. 2012; 30: S14-17.

48. Gurler A, Boyvat A, Tursen U. Clinical manifestations of Behçet's disease: an analysis of 2147 patients. Yonsei Med J. 1997; 38: 423-7.

49. al-Dalaan AN, al Balaa SR, el Ramahi K, et al. Behçet's disease in Saudi Arabia. J Rheumatol. 1994; 21: 658-61. 